\title{
Visión geográfica de la percepción de riesgos por peligros hidrometeorológicos extremos en Cuba
}

\author{
Geographic vision of the perception of risks due to extreme \\ hydrometeorological hazards in Cuba
}

\author{
Pablo Bayón-Martínez ${ }^{1}$ \\ Universidad de La Habana, Habana, Cuba \\ Lilia Susana Padilla y Sotelo ${ }^{2}$ \\ Universidad Nacional Autónoma de México, México
}

\begin{abstract}
Resumen
El conocimiento geográfico es base para la construcción teórica y práctica del espacio como concepción de medio ambiente, así como para la necesaria formación cultural ambiental de los actores sociales en los contextos de producción y reproducción de la vida. La comprensión de las particularidades geográficas del espacio donde trascurre la vida cotidiana del individuo coadyuva a la percepción de los riesgos por peligros hidrometeorológicos extremos. El artículo es resultado del análisis, desde una visión geográfica, del estudio de percepción nacional de riesgos por peligros hidrometeorológicos de 2009-2011 en Cuba, con la inclusión de mapas temáticos afines, aporte que se incorpora a los esfuerzos de la Agencia de Medio Ambiente en los estudios sociales del ambiente, la gestión de riesgos de desastres y la educación geográfica local.
\end{abstract}

Palabras clave: peligros hidrometeorológicos; percepción de riesgo; vulnerabilidad social; formación cultural ambiental, educación geográfica.

\section{Abstract}

Geographical knowledge is the basis for the theoretical and practical construction of space as a conception of the environment, as well as for the necessary environmental cultural formation of social actors in the contexts of production and reproduction of life. The understanding of the geographical

1 Doctor en Ciencias Geográficas. Profesor Titular, Investigador Auxiliar. Facultad de Geografía, Universidad de La Habana. Calle L No. 353 (6to piso) e/ 23 y 21, Vedado, La Habana, Cuba. CP-10400. Correo electrónico: pablo.bayon@geo.uh.cu/pabamar@yahoo.com

2 Dra. en Geografía. Investigadora Titular de Tiempo Completo del Instituto de Geografía, Departamento de Geografía Social, Universidad Nacional Autónoma de México (UNAM). Circuito Exterior s/n, Ciudad Universitaria, Coyoacán, C.P. 04510, Ciudad México (CDMX), México. Correo electrónico: padilla@igg.unam.mx 
particularities of the space where the daily life of the individual elapses contributes to the perception of the risks brought by extreme hydrometeorological hazards. The article is the result of the analysis, from a geographical perspective, of the study of Cuba's national perception of risks from hydrometeorological hazards for the period 2009-2011, with the inclusion of related thematic maps. It aims at contributing to Cuba's Environmental Agency efforts in environment social studies, risk management of disasters and local geographic education.

Keywords: Hydrometeorological hazards; Risk perception; Social vulnerability; Environmental cultural formation; Geographical education.

\section{Introducción}

La etapa actual de transformación de la naturaleza se caracteriza por fuerzas estructurales que sistemáticamente degradan y llegan a exceder la capacidad de esta de asimilar la producción humana, por lo que ponen en movimiento una serie impredecible, pero interactiva y expansiva de fracturas sociogeoecológicas (Mateo, 2013), lo que corrobora lo afirmado por Engels (2002, p. 151) acerca de que

No debemos, sin embargo, lisonjearnos demasiado de nuestras victorias humanas sobre la naturaleza. Esta se venga de nosotros por cada una de las derrotas que le inferimos. Es cierto que todas ellas se traducen principalmente en los resultados previstos y calculados, pero acarrean, además, otros imprevistos con los que no contábamos y que, no pocas veces, contrarrestan los primeros.

La estrategia adaptativa del hombre a los procesos naturales se da principalmente a través de una plataforma cultural (González, 1996), al ser la cultura un mecanismo básico de adaptación de la naturaleza, y que combina herramientas, formas de organización social y de construcción simbólicas (Maya, 1996).

Al estudiar los sistemas ambientales, la Geografía opera con la categoría de territorio, aquel sobre el cual se ejerce control político por determinados grupos sociales, con límites jurídicamente establecidos según cada país (estado, departamento, provincia, municipio, consejo popular, etc.) y, espacio geográfico, que precisa todo lo que acontece en la superficie terrestre, resultante de la actividad humana y la herencia de su historia natural, es decir, dado por la configuración de los componentes naturales y sociales (económicos, culturales, etc.), diferenciables y distinguibles intrínsecamente, por el carácter de la ocupación por los grupos humanos en período histórico (Santos, 1996; Mateo y da Silva, 2006; Mateo, 2013). 
Las categorías mencionadas constituyen referente de partida para el análisis de la percepción de riesgos hidrometeorológicos de los grupos humanos en sus territorios -desde una visión geográfica- a partir de la concepción de paisajes como geosistema de primer nivel en la relación sociedad-naturaleza, que aporta el conocimiento de la geografía local del espacio en que transcurre la vida cotidiana del sujeto, como premisa que incida en la percepción del sujeto con relación a los peligros hidrometeorológicos extremos, en el ejemplo de Cuba, y por ende, en sus modos de actuación cotidiana para la gestión de los riesgos en su comunidad.

Los estudios de percepción de peligros en Cuba de Espina et al. (2002), Núñez y Espina (2001), Núñez et al. (2008) y Almaguer (2008) revelan la trascendencia de los componentes socioculturales en torno a esta cuestión; visibilizan insuficiencias perceptivas territoriales y de baja percepción -alrededor del $50 \%$ de los encuestados- a los riesgos por peligros hidrometeorológicos extremos con respecto a la insuficiente evaluación a las causas de las afectaciones y sus consecuencias, por ejemplo, a la vida, la salud humana y la contaminación del agua, entre otros, marginando el conocimiento de las particularidades geográficas del espacio donde transcurre la vida cotidiana del sujeto como elemento que incide en la percepción de sus peligros y vulnerabilidad (GER-AMA, 2013).

Según datos de la Oficina Nacional de Estadística e Información (ONEI), desde 1791 hasta 2017, el país ha sido afectado por 116 huracanes, siendo la región occidental la que más veces ha sido azotada en 80 ocasiones (ONEI, 2018, p. 23). En los últimos tres lustros, el país recibió el impacto de 12 huracanes, los que han provocado pérdidas económicas por valor de 33648,9 millones de pesos cubanos, con daños notables en la infraestructura de producción y servicios, con más de 1,5 millones de viviendas afectadas (ob. cit., p. 49). Las pérdidas de vidas humanas, generalmente, están relacionadas con actitudes negligentes de las víctimas por no atender las normas de protección y seguridad durante estos eventos.

El propósito de este trabajo es contribuir a los estudios de percepción de riesgo de peligros hidrometeorológicos extremos, en particular, los asociados con fuertes vientos e inundaciones por intensas lluvias y/o penetraciones del mar ${ }^{3}$, desde una perspectiva geográfica, redimensionando los

3 A los que también denominaremos dentro del texto riesgos asociados con el viento-lluvia-mar, en alusión a los referidos eventos hidrometeorológicos extremos (N. de los A.). 
resultados del estudio de percepción nacional de 2009-2011 de la Agencia de Medio Ambiente (AMA) de Cuba, al incluir la visión geográfica en el análisis de los datos, como fundamento que aporta a los estudios de vulnerabilidad y a la identificación de pautas cognoscitivas y geográficas que han de tenerse en cuenta para la planificación y ejecución de acciones de educación geográfica local. En tal sentido, se destaca el papel de la Geografía local -como ciencia y enseñanza- para la comprensión de las relaciones que se producen en los espacios de producción/reproducción de la vida social y la singularidad geográfica del espacio donde transcurre la vida cotidiana ${ }^{4}$ del sujeto.

\section{Área de estudio}

La República de Cuba limita al norte con el Golfo de México, el estrecho de la Florida y el canal Viejo de Bahamas; al sur, con el Mar Caribe; al este, el paso de los Vientos que la separa de La Española; y por el oeste limita con el estrecho de Yucatán. Su posición geográfica tropical ${ }^{5}$-a la entrada del Golfo de México y muy cerca del continente norteamericanounido a su configuración alargada y estrecha en el sentido de los paralelos (Figura 1), ha determinado las principales particularidades climáticas del país, con predominio de clima cálido tropical con influencia marítima estacionalmente húmedo. Entre las principales características del clima cubano está la incidencia de huracanes, frentes fríos y sures, que modifican de forma notable el comportamiento de los parámetros meteorológicos y constituyen la principal amenaza a los subsistemas naturales y sociales. Los sures y los huracanes propician la ocurrencia de eventos de inundaciones por penetración del mar en amplios sectores costeros, fenómeno de particular interés, dado por el conocimiento previo de las futuras afectaciones por el ascenso del nivel medio del mar y la alta vulnerabilidad de las áreas costeras cubanas, donde se asienta el $10 \%$ de su población, distribuida en 232 asentamientos, según datos del Instituto de Planificación Física referidos por Planos, Vega y Guevara (2013: 80).

4 Vida cotidiana [...] "como el espacio y el tiempo en que se manifiestan, en forma inmediata, las relaciones que los hombres establecen entre sí y con la naturaleza en función de sus necesidades, configurándose así lo que hemos denominado sus condiciones concretas de existencia [...]" (Quiroga; 1986, p. 12-13)

5 Dado por la ubicación de sus puntos extremos norte y sur respectivamente, entre los $23^{\circ} 17^{\prime} 09^{\prime \prime}$ y los $19^{\circ}$ 49'36" de latitud norte, cercana al trópico de Cáncer. 
Figura 1. Localización geográfica del área de estudio.

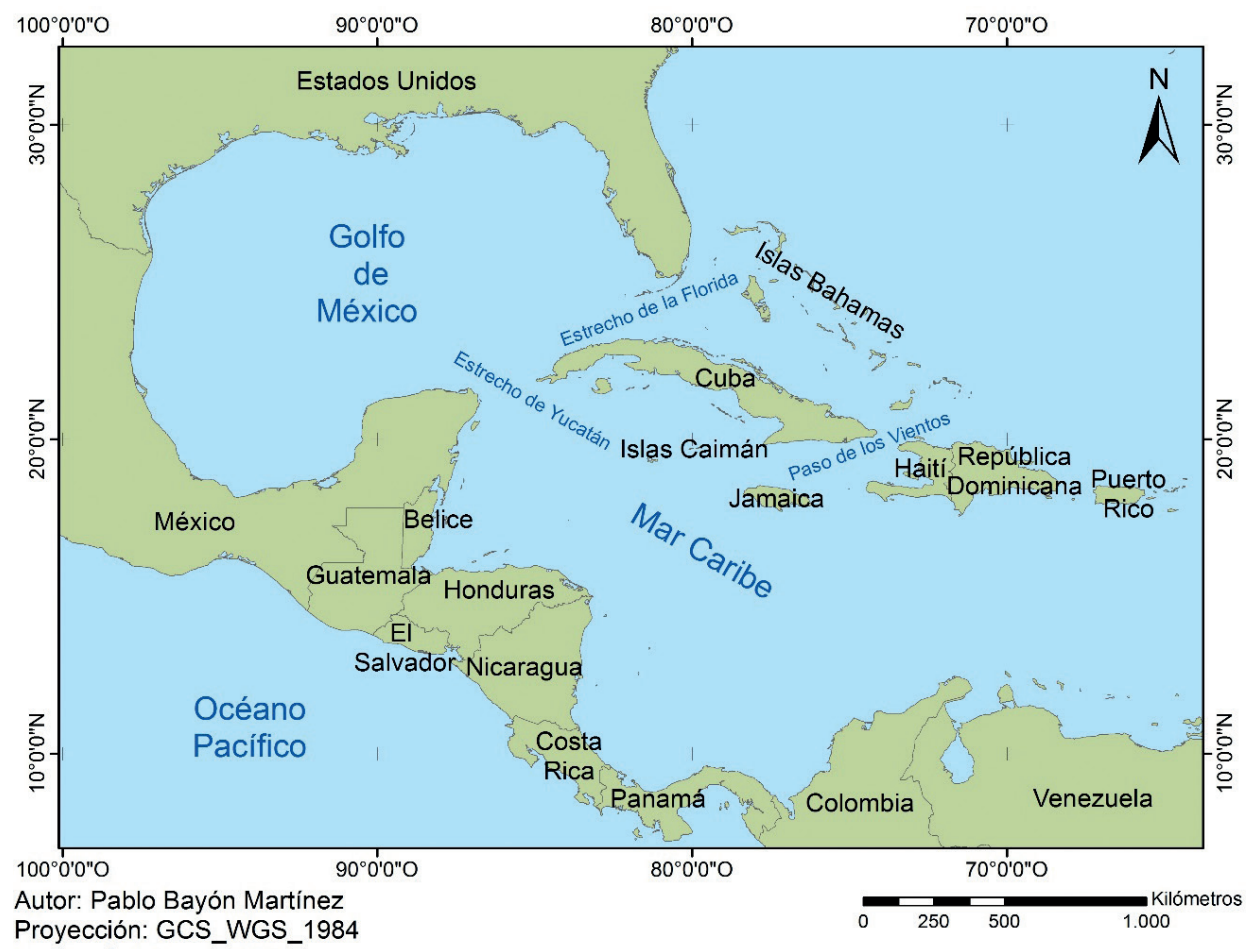

Fecha: Octubre de 2018

Fuente: elaboración propia

\section{Marco teórico-conceptual}

\section{El riesgo como construcción social: fundamentos de partida para la percepción de riesgo por peligros hidrometeorológicos extremos}

En el análisis contemporáneo de la percepción y gestión de riesgos se comprende que los riesgos ambientales son una construcción social, de configuración de vulnerabilidades que potencian su magnitud, dado por la confluencia espacio-temporal del medio ambiente y los desastres, en los espacios de producción/ reproducción social como fenómeno humano.

El hombre histórico vive en determinada situación de desarrollo en un espacio concreto, bajo determinadas relaciones sociales con otros hombres; por ello, el reflejo subjetivo de la realidad "es el proceso activo 
mediante el cual el individuo adquiere información sobre el ambiente que le rodea" (Almaguer, 2008, p. 40).

Las anteriores visiones pautan la importancia del conocimiento de las particularidades geográficas del espacio donde transcurre la vida cotidiana del individuo, que implica comprender y adaptarse de forma transformadora al territorio, lo que coadyuva a mejorar la percepción de riesgo de estudio, argumento que fue contrastado empíricamente desde la práctica profesional de los autores y, en grupo de estudio en Cuba.

El concepto de percepción ambiental dado por Peña (citado por Tserej y Febles, 2015), consiste en "aquel proceso cognoscitivo holístico e integral, que tiene un carácter selectivo, histórico y social [...] que permite el conocimiento del mundo y se produce en la interacción con éste; está, además, en constante cambio y necesita actualizarse sistemáticamente [...]" (p. 42) a través de la enseñanza. Se comprende que, depende -en gran medida- de la actividad de las personas que median su relación con el entorno $\mathrm{y}$, “[...] se encuentra relacionada con el sistema de sentidos sicológicos y vivencias que poseen las personas de su medio ambiente" (ob. cit., p.43).

Por ende, las percepciones tienen carácter histórico-concreto, pues representan -como proceso- un aprendizaje social en relación con el lugar que ocupa el individuo en el sistema de relaciones sociales en el cual se desarrolla, vinculado con el espacio concebido como hábitat.

La percepción de las particularidades geográficas del lugar ${ }^{6}$ ha ocupado protagonismo en el estudio de los riesgos naturales, sobre todo en Estados Unidos, donde algunos geógrafos como White y Kates investigaron durante los años 60 y 70 del pasado siglo, la percepción popular del riesgo de inundaciones, ofreciendo pautas para evaluar la percepción de la probabilidad de accidentes de los sujetos de indagación, así como sus experiencias para la adopción de respuestas ante el peligro respectivo. Con posterioridad, estas investigaciones se extendieron a una amplia gama de fenómenos naturales: sequías, tormentas, terremotos y erupciones volcánicas (Bayón, 2012, p. 11-12).

En los 70 del siglo pasado, a partir de un enfoque que evidencia una mayor preocupación por examinar las respuestas sociales e institucionales,

6 Se refiere a la unidad territorial (espacio) de significancia identitaria y de pertenencia de los diferentes sujetos individual y colectivo, en la producción y reproducción de la vida social, de identificación espacial y simbólica de la población con el territorio (Boisier, 2004; Mateo, 2013; Ojeda et al., 2014). 
algunos autores ingleses como Wisner, Westgate y O'Keefe (1977) "utilizaron una aproximación que partía del conflicto social para examinar la evolución de la vulnerabilidad a desastre" (citados por Maskrey, 1993, p. 3 ). Durante la década de los 70 y principios de los 80 , autores como Wenger (1978) y Hewitt (1995) revelaron lo importante de los condicionantes sociales para la gestión de desastres.

A partir de 1990 se hizo visible un significativo cambio en la concepción de los desastres. El riesgo se reconoce como un elemento sustancial para entender la construcción social de los desastres (Plapp, 2001; Sjöber, 2003; Cardona, 2003; Gellert de Pinto, 2012); comprendiéndose que las vulnerabilidades sociales, en particular, las relacionadas con el sujeto como ente individual y colectivo constituyen factores clave para la gestión de riesgos de desastres, en particular los relacionados con el desconocimiento de las particularidades geográficas del espacio en que transcurre la vida cotidiana del individuo, que lo hace o no, vulnerable ante la ocurrencia de eventos meteorológicos extremos a partir de su percepción y la adopción de modos de actuación social de adaptación a los mismos para la reducción de sus efectos.

Calderón (2001) sintetiza en su obra otras aportaciones conceptuales importantes, dentro de las cuales se encuentra la idea de que los fenómenos naturales -o los denominados agentes destructivos- no fueran considerados más como la causa, sino "como un precipitador para la crisis y la procedencia del desastre, directamente relacionada al contexto social" (ob. cit., p.2).

Calero y Santana (2001) aportan aspectos importantes al estudio de la percepción de riesgo. En sus reflexiones expresan que la percepción de riesgos involucra " [...] los valores, las tradiciones, los estereotipos, las vivencias y los conocimientos, que tienen los individuos sobre determinados aspectos o fenómenos de la vida" (ob. cit., p.54). Estas ideas que revelan algunos rasgos de la percepción de riesgo tales como la relación -del sujeto- con un evento adverso o su amenaza, así como el proceso sociocultural e histórico, que toma en cuenta los conocimientos, los valores y vivencia del individuo en la sociedad. No obstante, marginan el reconocimiento de las dimensiones espacio - temporales que condicionan el riesgo, es decir, las particularidades geográficas y su dinámica, como factor de vulnerabilidad del espacio en que transcurre la vida cotidiana del individuo. 
La percepción ambiental, en el amplio sentido, contiene la percepción de riesgo entendida por Wiedeman (1993), como:

la capacidad que tiene una persona para interpretar una situación potencialmente dañina para la salud o la vida propia o de otros, sobre la base de experiencias previas y en proyecciones futuras, que pueden variar de una opinión vaga a una firme convicción (p. 3).

Esta perspectiva marcó el curso de la investigación base, concibiéndose -como concepto operativo- que la percepción de riesgo de peligros hidrometeorológicos extremos significa revelar el grado de vulnerabilidad del sujeto individual y colectivo, a partir del conocimiento de las particularidades geográficas y su dinámica, del espacio donde transcurre su vida cotidiana ante la amenaza concreta, como alternativa que favorece la toma decisiones y modos de actuación oportunas antes, durante y posterior a su manifestación, minimizando las previsibles consecuencias para él y su familia.

\section{Consideraciones metodológicas.}

Se incorpora la dimensión geográfica del espacio donde transcurre la vida cotidiana del sujeto con relación al tipo de relieve predominante, paisaje geográfico y particularidades de la zona costera según grado de inundación, lo que significa la consideración de la geografía local en el análisis de la vulnerabilidad asociada con la dinámica del sistema natural en su contexto y la percepción de los riesgos referidos, lo que propiciará la asunción de criterios para el diseño e implementación de estrategia educativa geográfica -por demás ambiental-, dirigida a la formación ambiental del sujeto para la reducción del riesgo.

El desarrollo de la investigación (Figura 2) se llevó a cabo en una secuencia investigativa de tres momentos:

Figura 2. Esquema de secuencia investigativas

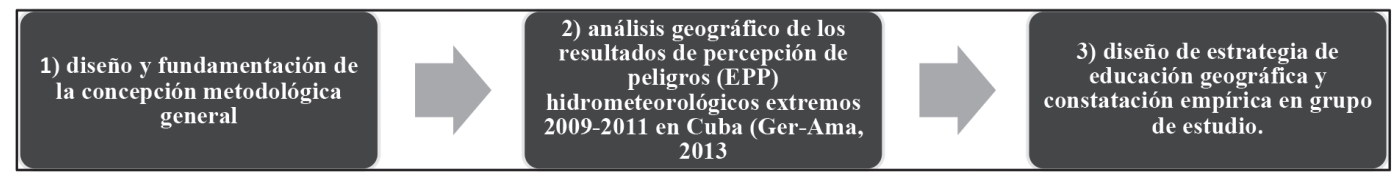

Fuente: elaboración propia de los autores 
Cabe enfatizar que aquí se exponen los resultados que corresponden al segundo momento de la investigación, en relación con el análisis de los datos del estudio nacional de percepción de riesgo por peligros hidrometeorológicos extremos de 2009-2011 (GER-AMA, 2013), del que no existen antecedente en el país, con entrevista aplicada a 16626 individuos, representativo del $0,14 \%$, aproximadamente, de la población residente en el período del estudio (ONEI, 2012: 92). Se analiza la percepción obtenida por municipios, conforme con las particularidades geográficas generales de sus territorios, según el tipo predominante de relieve (llanura-alturamontaña), de paisaje geográfico ${ }^{7}$ y el grado de inundación costera, siguiendo el esquema metodológico que se describe en la Figura 3, como aporte y complemento al estudio nacional. La distribución espacial de la percepción por municipios se representa conforme con los tres grupos de percepción identificados, concebidos en el diseño general de indagación (GER-AMA, 2013; Bayón, 2016a): Grupo I (alta), que refieren información y modos de actuación favorable ante el peligro; Grupo II (media), correspondiente a la percepción cercana a la realidad, pero insuficiente; y, Grupo III (baja), de percepción errónea o ninguna del riesgo y las maneras de enfrentarlo (López-Callejas y Núñez, 2011; López-Callejas, Núñez y Godefoy, 2013).

Se obtuvieron mapas, que más adelante se presentan, que constituyen primicia en cuanto al enfoque de los estudios de percepción de riesgos en la Agencia de Medio Ambiente de Cuba y, herramienta para la gestión pública de los tomadores de decisiones y el diseño de actividades de educación geográfica.

El estudio se complementó con otros procederes estadísticos, mediante el programa computarizado IBM SPSS v.22 (Statistic Package Social Sciences), propiciando el cruzamiento en tablas de contingencia y de frecuencia por unidad territorial descrita, según las variables geográficas de interés, y las particularidades sociodemográficas (edad, sexo, nivel de instrucción, tiempo de residencia, entre otros) de los entrevistados. Los mapas se elaboraron, empleando las herramientas del Sistema de Información Geográfica QGIS 2.14.3. (Bayón, 2016b).

7 De acuerdo con la clasificación y mapa del Nuevo Atlas Nacional de Cuba (IG e IGG, 1989). 
Pablo Bayón-Martínez - Lilia Susana Padilla y Sotelo Visión geográfica de la percepción de riesgos por peligros hidrometeorológicos extremos en Cuba

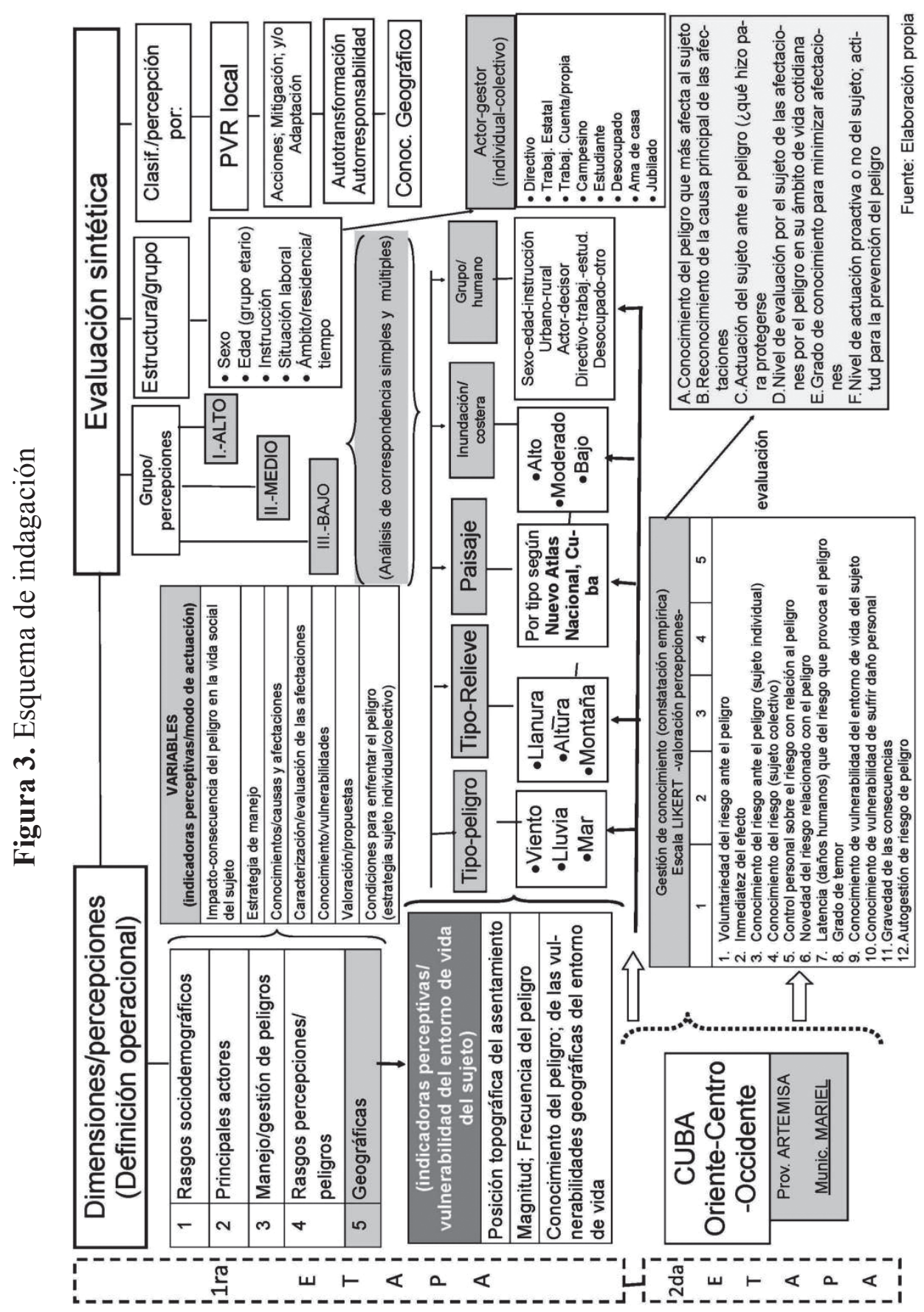


Los resultados porcentuales de percepción por municipios: alta, media o baja, por cada evento relacionado con el viento, la lluvia o el mar, se asumieron cualitativamente contrastando los valores porcentuales de percepción alta y la sumatoria de la media y baja percepción, conforme la tabla de criterio (Tabla 1), consensuada en taller con miembros del grupo asesor y la consulta con especialistas del ámbito de la geografía como ciencia y enseñanza, con calificación de grado científico y/o académico, y categoría superior de investigación y docente, respectivamente.

Tabla 1. Rangos porcentuales de percepción de cada peligro de estudio para la clasificación de percepción general por cada municipio y provincia del país

\begin{tabular}{|c|c|c|c|c|}
\hline \multirow{2}{*}{$\begin{array}{c}\text { Clasificación/ } \\
\begin{array}{c}\text { Percepción } \\
\text { general }\end{array}\end{array}$} & \multicolumn{3}{|c|}{ Rango porcentual de percepción } \\
\cline { 3 - 5 } & & ALTA & MEDIA & BAJA \\
\hline \multirow{2}{*}{ ALTA } & - & $\geq 65,0$ & \multicolumn{2}{|c|}{$\leq 35,0$} \\
\cline { 2 - 5 } & Alta & - & - & $\leq 11,7$ \\
\cline { 2 - 5 } & Media & - & - & $\geq 23,3$ \\
\hline \multirow{2}{*}{ MEDIA } & & $\leq 49,0 \leq 64,9$ & \multicolumn{2}{|c|}{$\geq 35,1 \leq 51,0$} \\
\cline { 2 - 5 } & Baja & - & - & $\geq 34,0$ \\
\hline \multirow{2}{*}{ BAJA } & - & $\leq 35,0 \leq 48,9$ & \multicolumn{2}{|c|}{$\geq 51,1$} \\
\cline { 2 - 5 } & Media & - & $\geq 34,0$ & - \\
\hline
\end{tabular}

Fuente: elaboración propia.

La clasificación general de percepción: alta, media, baja; se fijó por exceso, dadas las insuficiencias perceptivas a los peligros estudiados y por lo significativo de esta información para la adopción de acciones educativas e institucionales y para la gestión de los riesgos estudiados, conforme los siguientes criterios:

- Alta: sí el resultado porcentual de percepción "alta" respectivo, es igual o superior a $65,0 \%$ o la sumatoria de percepción "media + baja" es igual o inferior a 35,0\%. También se clasifica de alta, en caso de que la percepción "baja" respectiva, sea igual o inferior a $11,7 \%$. Se clasifica de media, en similar circunstancia a lo anterior, pero en los casos que el resultado de "baja" percepción respectiva, igual o superior a $23,3 \%$. 
- Media: en los casos en que el rango de la percepción "alta" oscile entre igual o superior a $49,0 \%$ e igual o inferior a $64,9 \%$; o que, el rango de la percepción "media+baja" esté en el rango de igual o inferior a $35,1 \%$ hasta igual o inferior a $51,0 \%$. En caso de que la percepción "baja" del evento respectivo, sea igual o superior a 34,0 $\%$, se asume como clasificación general de baja percepción.

- Baja: en los casos en que la sumatoria de las percepciones "media y alta" sea igual o superior a $51,1 \%$. En caso de que la percepción "media" sea igual o superior a 34,0 \%, se clasificó como media a la percepción general.

\section{Resultados generales}

\section{Visión geográfica del estudio de percepción de riesgo por peli- gros hidrometeorológicos extremos en Cuba}

El clima en Cuba al parecer, como afirman Fernández et al. (2009) se está "[...] volviendo más extremo [...]" (ob. cit., p. 173) en lo que concierne a los ciclones tropicales y tormentas locales severas con caída de granizo, formación de tornados con fuertes vientos, "como fenómenos meteorológicos a los que se asocia el mayor peligro de desastre" (Planos, Vega y Guevara, 2013, p. 23), durante las tres últimas décadas. De acuerdo con Fernández et al. (2009), los eventos de lluvias intensas de la década de los 80 fueron los mayores reportados en el siglo XX, mientras que la ocurrencia de tornados y los eventos intensos se han hecho más frecuentes desde 1977. Adicionalmente, se han incrementado las inundaciones por penetraciones del mar moderadas y fuertes ${ }^{8}$, asociadas con el impacto de "siete huracanes intensos entre el 2001 y el 2011, cifra que nunca se había registrado en década alguna desde 1791 hasta el presente" (Planos, Vega y Guevara, 2013, p. 75).

8 Las inundaciones costeras se clasifican en ligeras, moderadas y fuertes combinando descriptores cualitativos y cuantitativos. En Cuba, los tramos costeros - cuatro al Norte e igual cantidad al Sur- son diferenciables por sus particularidades físico-geográficas, amplitud y profundidad de la plataforma insular, desigual manifestación de patrones meteorológicos que inciden en la frecuencia y magnitud de eventos de inundación, entre otros, lo que determina su agrupamiento en cuatro tipos de costas, según el alcance horizontal del mar hacia el interior (Hidalgo, Mitrani y Pérez, 2017). Por ejemplo: la costa tipo 1, con inundación de 0-500 m se clasifica de inundación "ligera"; de 501-1000 m "moderada", mayor de 1000 m "fuerte" (ob. cit., pp. 212-213). 
Los últimos huracanes que afectaron al país -previo al estudio nacional- ocurrieron en el $2008^{9}$, constituyendo record histórico de huracanes de gran intensidad para un mismo año, pues fueron tres de gran intensidad ${ }^{10}$, dos de categoría 4 y uno de categoría 3 (Gustav, Ike y Paloma, citados por Planos, Vega y Guevara (2003).

La ocurrencia de ciclones -en los últimos 200 años- ha sido más frecuente hacia el occidente y centro del país (Figura 4-A), hecho que se refleja, preliminarmente, en los resultados de percepción total por parte de la población. Otro elemento de consideración es la incidencia de frentes fríos de diferentes intensidades ${ }^{11}$, dado que con los de mayor intensidad, se asocian eventos hidrometeorológicos intensos -coincidentemente de mayor frecuencia e incidencia- hacia la región occidental y centro del país, tal como se describe en la Tabla 2.

Figura 4-A: Cuba: cantidad de huracanes por regiones (1791-2017)

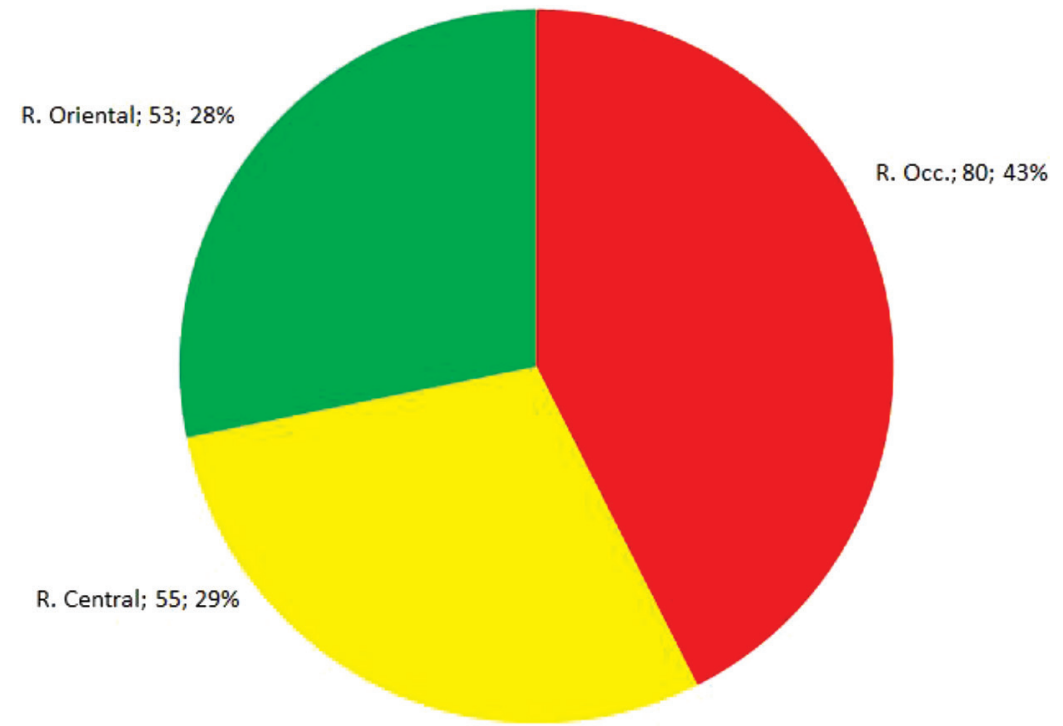

Fuente: elaborado por el autor a partir de datos del AEC (ONEI, 2018)

9 Se refiere como antecedente al período previo al estudio de percepción de referencia entre 2009-2011.

10 De acuerdo con la escala de huracanes de Saffir-Simpson que clasifica los ciclones según la intensidad del viento: SS-1 (119-153 km/h); SS-2 (154-177 (Km/h); SS-3 (178-208 Km/h); SS-4 (209-251 Km/h); SS-5 (>251 Km/h) (ONEI, 2012, p. 48).

11 Se clasifican según la velocidad del viento en: débiles $(<35 \mathrm{~km} / \mathrm{h})$, moderados (entre 36 y $55 \mathrm{~km} / \mathrm{h})$ y fuertes $(>55 \mathrm{~km} / \mathrm{h})$. 
Figura 4-B: CUBA. Relación porcentual de huracanes que han azotado a las regiones entre 2001-2011 (9-10 años -aproximadamente- antes del estudio de percepción de la Ama)

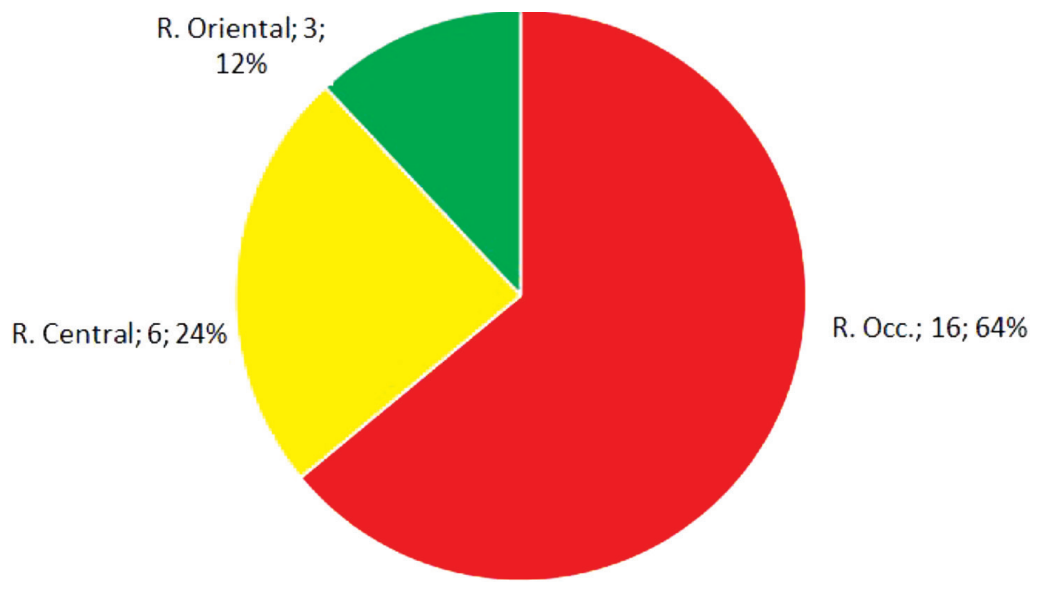

Fuente: elaborado por el autor a partir de datos del AEC (ONEI, 2014)

Tabla 2. Número de veces que cada región ha sido azotada por frentes fríos de diferentes intensidades en período previo al estudio de percepción de peligros desarrollado por la AMA

\begin{tabular}{|c|c|c|c|c|}
\hline \multirow{2}{*}{ REGIONES } & \multicolumn{4}{|c|}{ 1975/76 a 2014/15 } \\
\cline { 2 - 5 } & TOTAL & Débiles & Moderados & Fuertes \\
\hline CUBA & 2068 & 1572 & 466 & 30 \\
\hline R. Occidental & 841 & 494 & 327 & 20 \\
\hline R. Central & 675 & 584 & 84 & 7 \\
\hline R. Oriental & 552 & 494 & 55 & 3 \\
\hline
\end{tabular}

Fuente: Anuario Estadístico de Cuba 2017, edición 2018 (ONEI, 2018)

A escala nacional, el 47,0 \% de los encuestados reconocen al peligro asociado con fuertes vientos, como el de mayor prioridad, le siguen las inundaciones por intensas lluvias con 29,3\%, y por el mar, el 23,6 \%, lo que es contrario a los efectos provocados por cada uno de acuerdo con la memoria histórica local inferido por líderes o sujetos de mayor tiempo de residencia en la comunidad. 
Son observables los relativamente altos índices de percepción "media" y "baja" en conjunto (cercano o superior al $50 \%$ ) para todos los peligros de estudio en el país (Figura 5), que resultan significativo a pesar de los logros obtenidos en los ámbitos de educación general y ambiental, al parecer insuficientes, reflejo de la multicausalidad en el carácter de las percepciones. Por otra parte, llama la atención los resultados globales del estado de la "percepción" de la población por regiones y provincias, con favorables resultados de percepción hacia occidente, coincidente con las áreas de mayor afectación histórica de eventos meteorológicos extremos (Bayón, 2012).

Figura 5. Percepción total de riesgo por peligros hidrometeorológicos extremos (2009-2011): fuertes vientos, inundaciones por intensas lluvias y por penetraciones del mar.

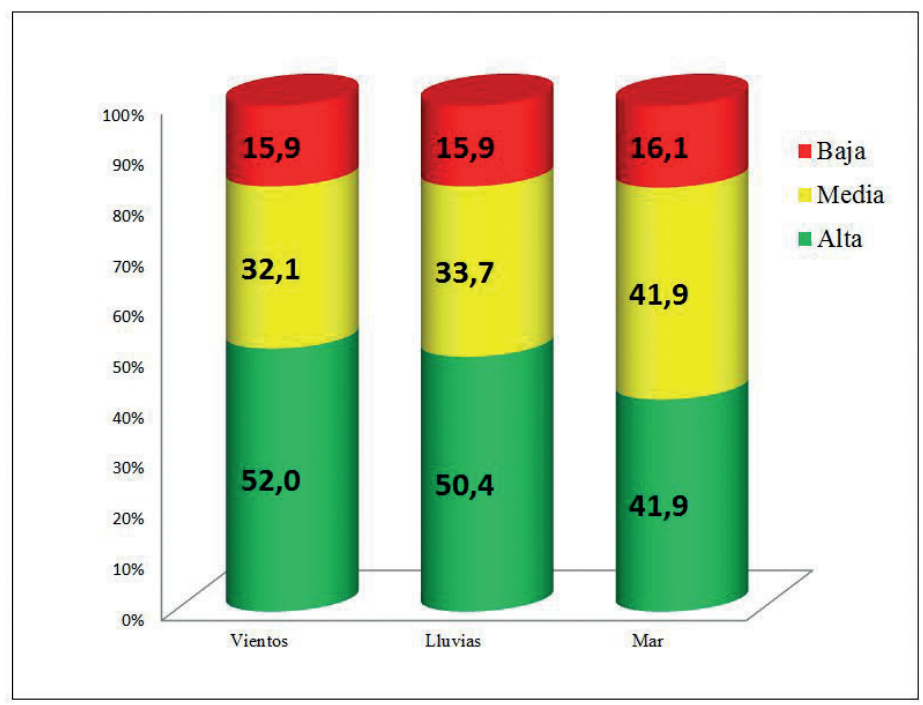

Fuente: Elaboración propia a partir de la base de datos del estudio nacional de percepción de riesgos por peligros hidrometeorológicos extremos de 2009-2011, Cuba (GER-AMA, 2013).

No obstante, los resultados por provincias son contrastantes aún para una misma región, como es el caso de la provincia de Matanzas con resultados muy inferiores relativamente en la región occidental, aspecto de gran interés para el diseño de acciones de educación y comunicación social. Los menores índices fueron registrados hacia el oriente del país. 
Pablo Bayón-Martínez - Lilia Susana Padilla y Sotelo Visión geográfica de la percepción de riesgos por peligros hidrometeorológicos extremos en Cuba

En la Tabla 3 se describen los resultados de percepción por regiones y provincias de Cuba, donde resulta llamativo el predominio de territorios con percepción media-baja (que supera el $50 \%$ del total de los encuestados).

Tabla 3. Cuba: descripción de la percepción riesgo por peligros hidrometeorológicos extremos por regiones ${ }^{12}$ y provincias $(\%)$

\begin{tabular}{|c|c|c|c|c|c|c|c|c|c|}
\hline \multirow[b]{2}{*}{ Territorios } & \multirow[b]{2}{*}{$\begin{array}{c}\text { Perc. } \\
\text { ALTA } \\
(16-26 \\
\text { ptos }) \\
\end{array}$} & \multirow{2}{*}{$\begin{array}{c}\text { Viento } \\
\text { Perc. } \\
\text { MEDIA } \\
\text { (27-37 } \\
\text { ptos) }\end{array}$} & \multirow[b]{2}{*}{$\begin{array}{l}\text { Perc. } \\
\text { BAJA } \\
(38-48 \\
\text { ptos }) \\
\end{array}$} & \multicolumn{2}{|c|}{ Lluvia } & \multirow[b]{2}{*}{$\begin{array}{l}\text { Perc. } \\
\text { BAJA } \\
(38-48 \\
\text { ptos) } \\
\end{array}$} & \multirow[b]{2}{*}{$\begin{array}{c}\text { Perc. } \\
\text { ALTA } \\
\text { (16-26 } \\
\text { ptos) }\end{array}$} & \multirow{2}{*}{$\begin{array}{c}\text { Mar } \\
\text { Perc. } \\
\text { MEDIA } \\
(27-37 \\
\text { ptos }) \\
\end{array}$} & \multirow[b]{2}{*}{$\begin{array}{c}\text { Perc. } \\
\text { BAJA } \\
(38-48 \\
\text { ptos })\end{array}$} \\
\hline & & & & $\begin{array}{l}\text { Perc. } \\
\text { ALTA } \\
(16-26 \\
\text { ptos })\end{array}$ & $\begin{array}{c}\text { Perc. } \\
\text { MEDIA } \\
(27-37 \\
\text { ptos })\end{array}$ & & & & \\
\hline & & & \multicolumn{3}{|c|}{ REGIONES } & & & & \\
\hline Occidental & 56,1 & 36,0 & 7,9 & 51,3 & 40,7 & 8,0 & 45,8 & 45,9 & 8,3 \\
\hline Central & 54,3 & 26,4 & 19,3 & 52,3 & 28,3 & 19,4 & 44,9 & 54,6 & 58,5 \\
\hline \multirow[t]{2}{*}{ Oriental } & 49,2 & 33,2 & 17,6 & 49,2 & 33,3 & 17,6 & 38,9 & 43,3 & 17,8 \\
\hline & & & \multicolumn{3}{|c|}{ PROVINCIAS } & & & & \\
\hline Pinar del Río & 84,3 & 14,6 & 1,1 & 79,8 & 18,7 & 1,5 & 75,3 & 23,2 & 1,5 \\
\hline Artemisa & 74,3 & 22,9 & 2,8 & 67,3 & 29,9 & 2,8 & 61,2 & 36,0 & 2,8 \\
\hline Mayabeque & 58,0 & 30,3 & 11,8 & 52,5 & 35,7 & 11,8 & 46,2 & 42,0 & 11,8 \\
\hline Matanzas & 31,9 & 53,7 & 14,4 & 28,6 & 56,9 & 14,6 & 24,2 & 60,7 & 15,1 \\
\hline Villa Clara & 46,2 & 34,7 & 19,1 & 42,1 & 38,5 & 19,4 & 33,3 & 47,3 & 19,4 \\
\hline Cienfuegos & 55,2 & 24,0 & 20,8 & 54,8 & 24,5 & 20,8 & 52,7 & 26,6 & 20,8 \\
\hline Sancti Spíritus & 55,7 & 28,4 & 15,9 & 54,3 & 29,9 & 15,9 & 46,1 & 37,9 & 16,0 \\
\hline Ciego de Ávila & 65,5 & 12,2 & 22,3 & 64,8 & 12,9 & 22,3 & 55,4 & 22,3 & 22,3 \\
\hline Camagüey & 55,7 & 30,0 & 14,3 & 55,3 & 30,5 & 14,2 & 44,3 & 41,3 & 14,4 \\
\hline Las Tunas & 62,5 & 29,4 & 8,1 & 58,7 & 33,2 & 8,1 & 50,5 & 41,4 & 8,1 \\
\hline Holguín & 46,0 & 45,7 & 8,3 & 44,6 & 47,0 & 8,4 & 39,2 & 52,3 & 8,5 \\
\hline Granma & 47,2 & 23,6 & 29,2 & 45,7 & 25,1 & 29,2 & 37,2 & 33,5 & 29,3 \\
\hline $\begin{array}{c}\text { Santiago de } \\
\text { Cuba }\end{array}$ & 41,4 & 43,4 & 15,2 & 46,0 & 38,7 & 15,3 & 30,9 & 53,8 & 15,3 \\
\hline Guantánamo & 45,9 & 25,9 & 28,2 & 47,4 & 24,9 & 27,7 & 34,5 & 36,3 & 29,2 \\
\hline $\begin{array}{l}\text { Isla de la } \\
\text { Juventud }\end{array}$ & 58,0 & 41,4 & 0,5 & 50,8 & 48,7 & 0,5 & 41,2 & 57,8 & 1,1 \\
\hline
\end{tabular}

Fuente: Elaboración propia a partir del procesamiento de base de datos de percepción nacional de riesgos por peligros hidrometeorológicos de 2009-2011 (GER-AMA, 2013).

12 Se asume el criterio de regiones -agrupándose por provincias- que establece el Instituto de Meteorología en Cuba: Región Occidental (Pinar del Río, Artemisa, La Habana, Mayabeque, Matanzas e Isla de la Juventud; Región Central: Villa Clara, Cienfuegos, Sancti Spíritus y Ciego de Ávila; Región Oriental: Camagüey, Las Tunas, Holguín, Granma, Santiago de Cuba y Guantánamo (N. del A.). 
Las provincias de Pinar del Río, Artemisa, Mayabeque e Isla de la Juventud muestran los mayores índices de percepción de riesgos estudiados, aunque difieren en cuanto al tipo (Bayón, 2016b). En la distribución geográfica de los resultados integrales de percepción se observan los menores resultados hacia las regiones orientales (Figura 6), muy relacionado con la menor afectación histórica de eventos extremos en dicha región previo al estudio nacional (ver Figura 4-B), lo que al parecer influyó en las afectaciones sufridas en sus territorios al paso del huracán Sandy -en noviembre de 2012- por Santiago de Cuba, dado por la relativa minimización del impacto de dicho fenómeno, estando en correspondencia con los resultados de percepción obtenidos en el estudio nacional (tabla 3).

Figura 6. Cuba: distribución de la percepción general de riesgo por peligros hidrometeorológicos extremos de 2009-2011 por provincias

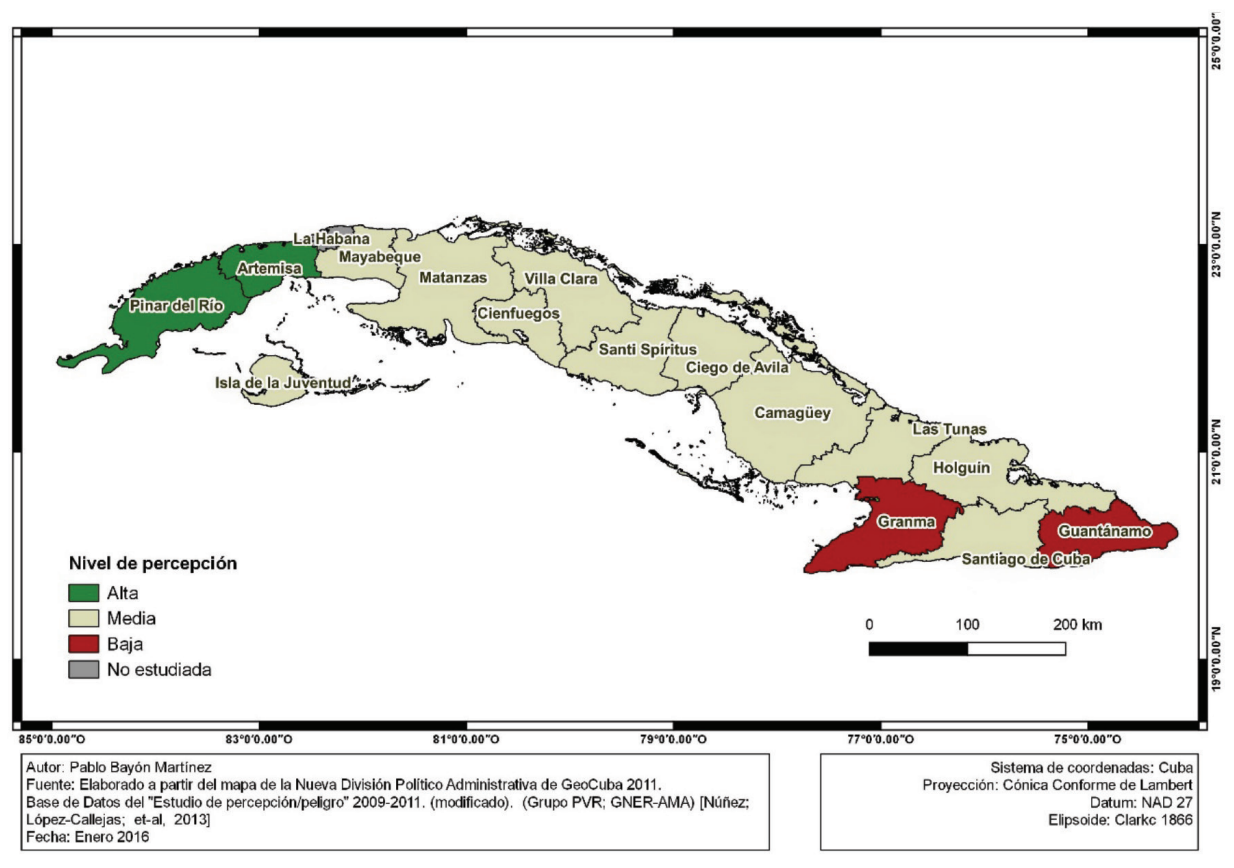

Fuente: elaboración propia 
Por el carácter insular de Cuba, el $65 \%$ de los municipios acceden directamente al mar, lo que los hace vulnerables a las inundaciones costeras por penetración del mar. En el estudio nacional se registró que la percepción de dichos peligros constituyó el de menor prioridad en la selección de los encuestados a escala nacional (3,0\%), lo que resulta comprensible dado que su efecto se concentra hacia las poblaciones que se asientan en litorales bajos, de menor proporción en el país, pero de alta significación por los más de 230 asentamientos costeros vulnerables por el ascenso previsto del nivel del mar por el cambio climático (Planos, Vega y Guevara, 2013).

En la Tabla 4 se describen la percepción del riesgo de acuerdo con el grado de inundación costera ${ }^{13}$, según municipio de residencia, con marcada significación porcentual de percepción (media a baja), aproximadamente, del $50 \%$ en municipios con moderado-alto y muy alto grado de inundación costera, lo que significa deficiencias perceptivas del peligro en cuestión.

Tabla 4. Percepción de riesgo por inundaciones del mar por municipios según grado de inundación costera

\begin{tabular}{|c|c|c|c|}
\hline \multirow{2}{*}{ Grado de inundación costera } & \multicolumn{3}{|c|}{ Nivel de percepción (\%) } \\
\cline { 2 - 4 } & Alta & Media & Baja \\
\hline Muy alto & 50,9 & 36,4 & 12,6 \\
\hline Moderado-alto & 42,6 & 42,1 & 15,3 \\
\hline Bajo & 39,1 & 46,7 & 14,2 \\
\hline No costero & 38,9 & 42,7 & 18,4 \\
\hline
\end{tabular}

Fuente: Elaborada a partir del procesamiento y reclasificación de base de datos de percepción nacional (GER-AMA, 2013).

En la Figura 7 se muestra la distribución espacial de percepción de riesgo por peligro de inundación costera por municipios; por el norte, se destacan extensos territorios entre La Habana y Las Tunas, Holguín y Guantánamo, con percepción media y baja, en sectores identificados con grado de inundación moderado-alto, por lo que constituyen áreas

13 Refiere Mitrani et al., 2011, citado por Planos, Vega y Guevara (2013, p.80) que, [...] "salvo el tramo costero aledaño al Golfo de Casilda-Cazones, el sur de las provincias orientales (Cabo Cruz-Punta de Maisí) y el comprendido entre Punta Maternillos y Gibara en todo el perímetro costero cubano, el peligro por inundaciones es de moderado a alto, y es muy alto en el Golfo de Batabanó, en el tramo Cabo Cruz-Punta María Aguilar y en el litoral de la ciudad de La Habana". 
con poblaciones de interés para la gestión educativa. Por otra parte, en la costa sur, son extensos los sectores costeros de muy alto grado de inundación donde la población refiere media a baja percepción al peligro en las provincias de Granma, Camagüey, Ciego de Ávila, Matanzas, Mayabeque e incluso de Pinar del Río, lo que acentúa el interés de formación de conocimientos ante la amenaza respectiva y la vulnerabilidad manifiesta en su percepción.

Son notables las áreas de alta percepción (más del 50 \%), en amplios sectores de Pinar del Río, Artemisa, Ciego de Ávila y Las Tunas.

Con relación al relieve, son las llanuras el tipo predominante $(80,6 \%)$ de los municipios del país; el 15,0\% de los municipios pueden considerarse "altos" y solo el 4,4 \%, constituyen municipios predominantemente de montaña. Los resultados de percepción con relación al impacto de fuertes vientos e inundaciones por intensas lluvias se describen en la Tabla 5.

Figura 7. Cuba: distribución de la percepción general de riesgo por peligro de inundación por penetraciones del mar según grado de inundación costera por municipios

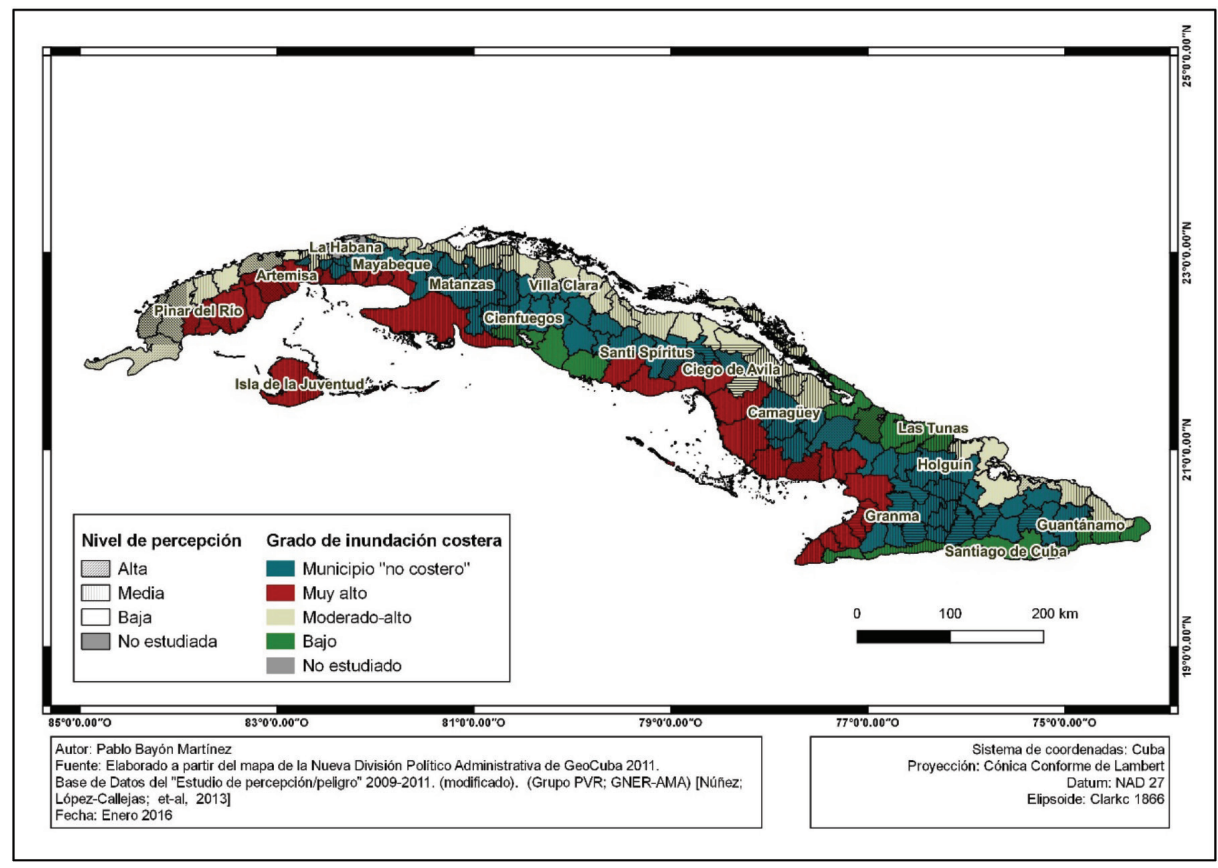


Tabla 5. Percepción de riesgo por peligro por fuertes vientos e inundaciones por intensas lluvias según relieve predominante por municipios

\begin{tabular}{|c|c|c|c|c|c|c|}
\hline \multirow{2}{*}{ Tipo de relieve } & & \multicolumn{4}{|c|}{ Nivel de percepción (\%) } & \\
\cline { 2 - 7 } & & \multicolumn{2}{|c|}{ Viento } & \multicolumn{2}{|c|}{ Lluvia } & \\
\cline { 2 - 7 } & Alta & Media & Baja & Alta & Media & Baja \\
\hline Llanura (0-200 msnm) & 53,6 & 31,0 & 15,4 & 51,3 & 33,2 & 15,5 \\
\hline Altura (201-500 msnm) & 43,1 & 38,2 & 18,7 & 45,5 & 35,7 & 18,8 \\
\hline Montaña $(>500 \mathrm{msnm})$ & 51,6 & 33,4 & 15,0 & 50,6 & 34,5 & 14,9 \\
\hline
\end{tabular}

Fuente: Elaboración propia a partir del procesamiento y reclasificación de base de datos de percepción nacional (GER-AMA, 2013), según tipo de relieve predominante por municipios.

Las poblaciones que viven en municipios con predominio de relieve llano y de montaña ofrecen los mayores resultados porcentuales de percepción para ambos peligros, en más de $50 \%$, mayormente relacionado con las condiciones geográficas del espacio donde transcurre la vida cotidiana del sujeto y con eventos meteorológicos extremos presentes en la memoria histórica local, refrendadas en las entrevistas realizadas (Bayón, 2016a, pp. 118-119), en particular las regiones occidental y central, con mayores acontecimientos ocurridos en los años previos al estudio de percepción nacional (ver Figura 4 A y B). Es de significar los valores medios y bajos de percepción, en municipios altos y de montaña, de las provincias de Guantánamo, Santiago de Cuba y Granma, así como hacia el centro del país, las provincias de Sancti Spíritus y Cienfuegos ${ }^{14}$.

La representación cartográfica del comportamiento espacial de la percepción general ${ }^{15}$, según el relieve (Figura 8), contribuyó a la identificación de vacíos de conocimientos en la población por provincias y municipios respectivamente, lo que aportó a la comprensión de las vulnerabilidades asociadas con el espacio donde transcurre la vida cotidiana, con incidencia en la gestión de riesgo de desastre por parte de las autoridades e instituciones gubernamentales y de la defensa civil. Es un resultado de significativo valor práctico, en lo que concierne al diseño de planes y gestión de riesgo

14 Por ejemplos; en la provincia Guantánamo, los municipios: Moa, Yateras, San Antonio del Sur y Manuel Támes; provincia Santiago de Cuba, municipios: San Luis, Palma Soriano y Santiago de Cuba; Granma, municipios: Guisa, Tercer Frente y Buey Arriba; provincia Sancti Spíritus, municipio Trinidad; provincia Cienfuegos, municipio Cumanayagua.

15 Se refiere a la percepción total a los peligros asociados con fuertes vientos e inundaciones por intensas lluvias y/o penetraciones del mar 
Pablo Bayón-Martínez - Lilia Susana Padilla y Sotelo

Geographic vision of the perception of risks due to extreme hydrometeorological hazards in Cuba

conforme las particularidades de cada territorio, así como para la implementación de políticas públicas de formación cultural ambiental a escala país, en general, y por municipio concreto, en particular.

Figura 8. Cuba: distribución de la percepción general de riesgo por peligros hidrometeorológicos extremos de 2009-2011, según tipo de relieve predominante por municipios

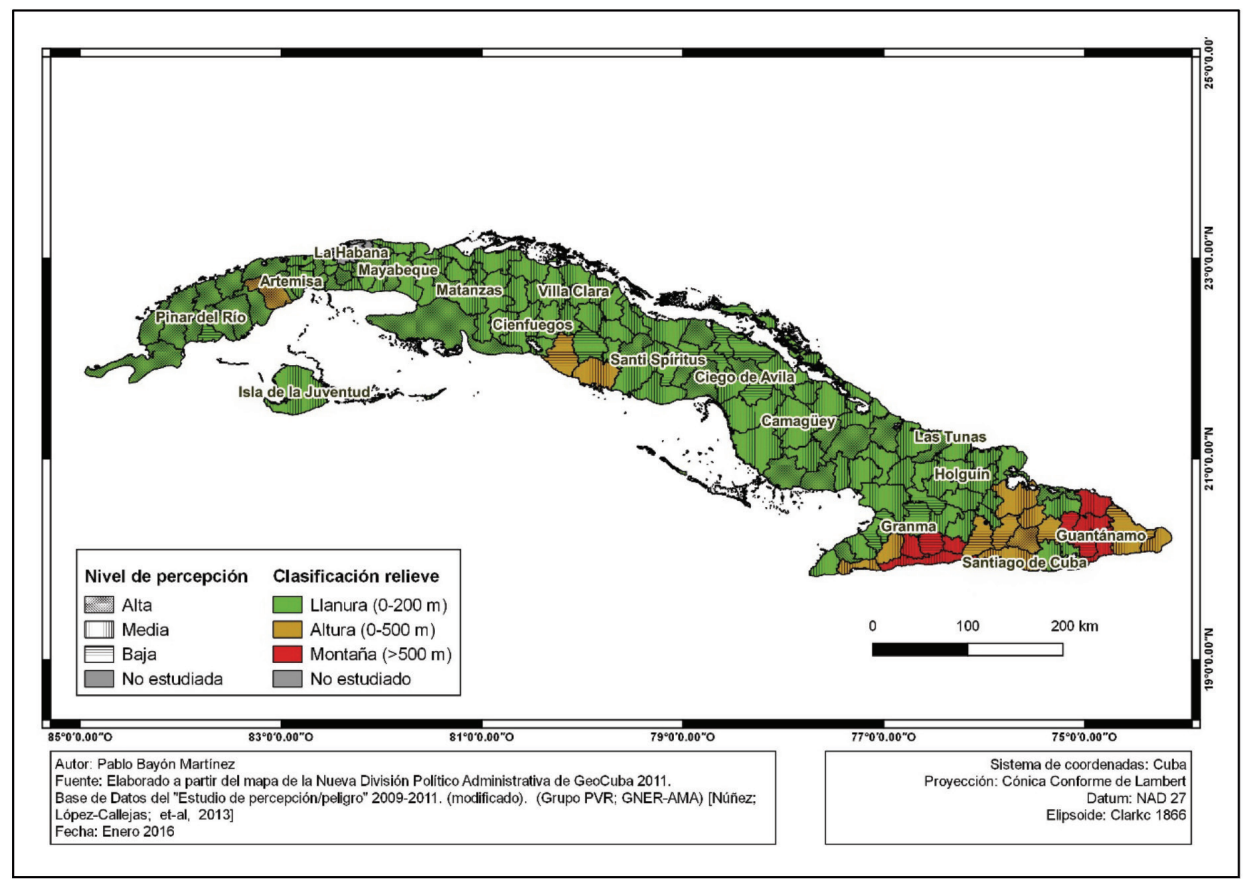

El paisaje natural ${ }^{16}$ constituyó la base teórica-metodológica para la articulación de los resultados de percepción de riesgos estudiados, por constituir el geosistema de primer nivel en la relación sociedad-naturaleza que aporta el conocimiento de la geografía local, de la dinámica de los sistemas naturales y del ámbito espacial de vida del individuo, lo que

16 Concepto básico de la Geografía de los Paisajes consistente en un "espacio físico y un sistema de recursos naturales en los cuales se integran las sociedades en la interacción sociedad-naturaleza [...] se concibe como un geosistema, el cual se define como el espacio terrestre, de todas las dimensiones, donde los componentes naturales se encuentran en una relación sistémica unos con los otros, y como una integridad definida, interactuando con la esfera cósmica y con la sociedad humana [...]” (Mateo, 2011, p. 1) 
contribuye al desarrollo de conocimientos, habilidades y capacidades para la gestión de riesgo como parte de la comprensión, atención y superación $\mathrm{de} \mathrm{su/s} \mathrm{vulnerabilidad/es} \mathrm{respectivas.}$

El análisis de percepción de riesgo de peligro por fuertes vientos e inundaciones por intensas lluvias ${ }^{17}$, por paisaje geográfico predominante de los municipios, refleja comportamientos perceptivos de interés, descritos en la Tabla 6, entre los que se destacan:

Tabla 6. Niveles de percepción de riesgo de peligro de estudio según paisaje geográfico predominante

\begin{tabular}{|c|c|c|c|c|c|c|}
\hline \multirow{3}{*}{ Paisaje geográfico } & & \multicolumn{4}{|c|}{ Nivel de percepción (\%) } & \multirow[b]{3}{*}{ Baja } \\
\hline & & \multicolumn{2}{|c|}{ Viento } & \multicolumn{2}{|c|}{ Lluvia } & \\
\hline & Alta & Media & Baja & Alta & Media & \\
\hline $\begin{array}{c}\text { Llanuras secas y } \\
\text { medianamente secas }\end{array}$ & 61,1 & 24,7 & 14,1 & 59,8 & 26,6 & 13,6 \\
\hline $\begin{array}{c}\text { Llanuras medianamente } \\
\text { húmedas }\end{array}$ & 54,3 & 31,1 & 14,6 & 51,9 & 33,5 & 14,6 \\
\hline $\begin{array}{l}\text { Colinas, alturas y montañas } \\
\text { secas }\end{array}$ & 36,6 & 29,9 & 33,6 & 35,2 & 31,9 & 32,9 \\
\hline $\begin{array}{c}\text { Depresiones intermontañosas, } \\
\text { colinas, alturas y montañas } \\
\text { bajas húmedas }\end{array}$ & 45,3 & 36,0 & 18,6 & 46,3 & 35,0 & 18,7 \\
\hline
\end{tabular}

Fuente: Elaboración propia a partir de procesamiento y reclasificación de base de datos de percepción nacional (GER-AMA, 2013), según paisaje geográfico predominante por municipios.

- $\quad$ Los mayores resultados perceptivos $(61,1 \%)$, con relación al peligro de fuertes vientos, para los entrevistados que viven en los paisajes de Llanuras secas y medianamente secas y las Llanuras medianamente húmedas $(54,3 \%)$.

- En relación con los peligros por intensas lluvias, los mayores índices de percepción alta se concentran en los paisajes de Llanuras secas y medianamente secas, y las Llanuras medianamente húmedas, con $59,8 \%$ y $51,9 \%$, respectivamente.

- Le siguen los paisajes de Depresiones intermontañosas, colinas, alturas y montañas bajas húmedas $(46,3 \%)$.

17 No se incluye al peligro de inundaciones/penetraciones del mar dado que no afecta a todas las comunidades y población del país. 
En el mapa (Figura 9) se muestra la distribución de la percepción por municipios según el paisaje predominante. Se observa que, dado por el predominio de los paisajes de llanuras hacia donde se concentra la mayor parte de la población y, la configuración alargada y estrecha del archipiélago cubano, la influencia climática marina afecta a todo el país, lo que homogeniza relativamente el comportamiento de sus variables. En tal sentido la variación de la percepción, especialmente -de acuerdo con la escala nacional-, es más contrastante hacia las áreas altas y de montaña. Con la excepción de los municipios montañosos de la provincia de Pinar del Río (municipios Minas de Matahambre, Viñales y La Palma), los municipios de Songo-La Maya (provincia Santiago de Cuba) y Frank País (provincia Holguín), con valores de alta percepción. En el resto del país el nivel de percepción es media a baja, cuestión de interés educativo para la gestión de riesgos en las comunidades.

Figura 9. Cuba: distribución de la percepción general de riesgo por peligros hidrometeorológicos extremos de 2009-2011, según paisaje geográfico predominante por municipios.

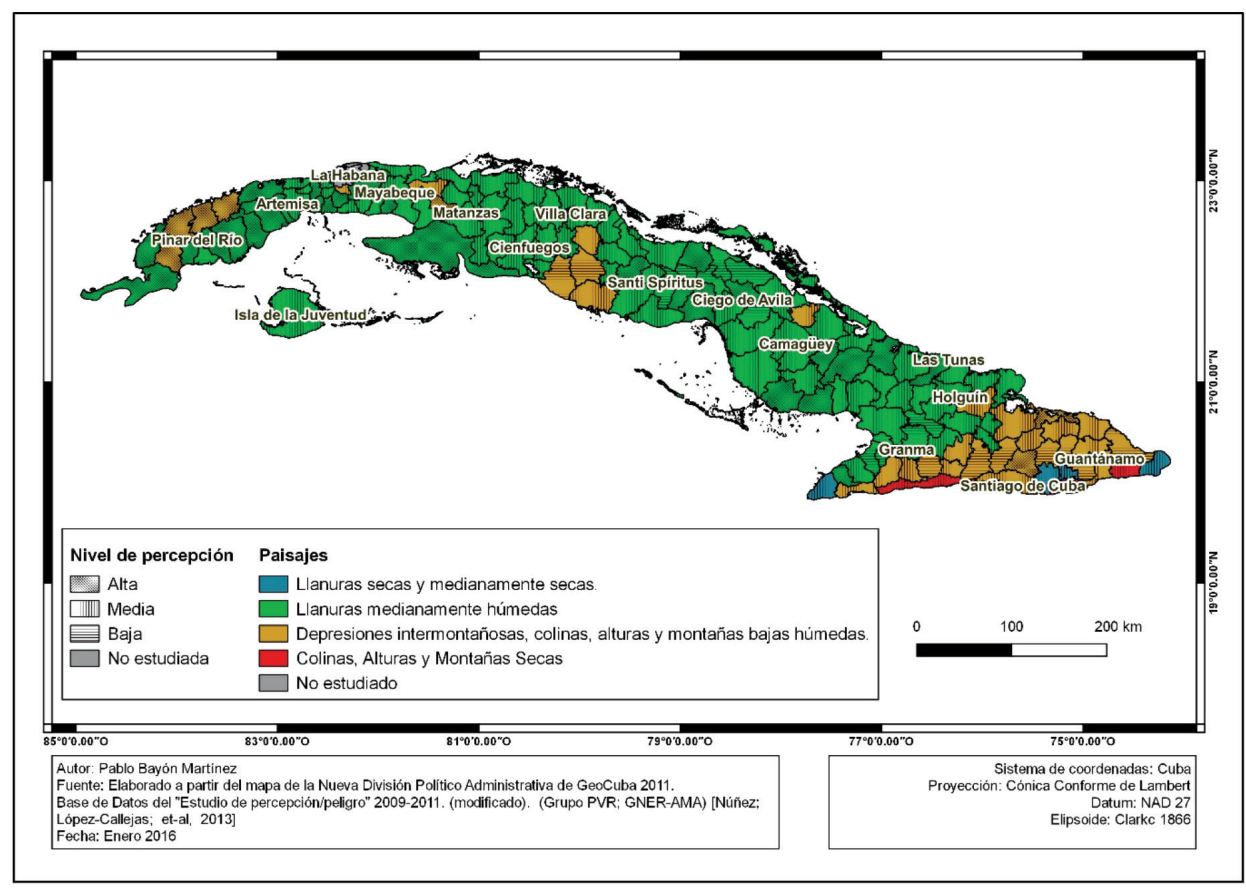


Los resultados obtenidos y representados en la cartografía contribuyen a la comprensión de las vulnerabilidades por territorio, relacionadas según las particularidades geográficas del espacio que rodean al ciudadano, como vía de control de los factores de riesgo como elemento preventivo y de adaptación al medio. Además, resalta el carácter contextual y local de la gestión del riesgo de peligro hidrometeorológicos para cada espacio de vida social conforme la configuración de su naturaleza geográfica.

\section{Conclusiones}

El saber geográfico, articulado con la identidad del sujeto como patrimonio de pertenencia al territorio concreto, contribuye a desarrollar la subjetividad y la percepción como base de la actitud ciudadana de responsabilidad social, en el fomento de una cultura de prevención y adaptación al cambio climático, de desarrollo local ambientalmente sostenible. Ello revela la necesidad de sistematizar e incorporar el conocimiento geográfico del espacio en que transcurre la vida cotidiana del individuo, como variable significativamente importante para elevar la percepción de riesgo.

La introducción de la visión geográfica en el análisis de la base de datos del estudio de percepción nacional de riesgos por peligros hidrometeorológicos extremos de 2009-2011 en Cuba permite sistematizar y revelar su comportamiento espacial relacionado con el tipo de relieve, paisaje geográfico predominante y por zona de inundación costera, además, por provincias y municipios, lo que contribuye a la identificación de pautas cognoscitivas y geográficas que deben tenerse en cuenta para la planificación y ejecución de acciones de educación geográfica local. Por otra parte, coadyuvó a la representación cartográfica y comprensión espacial del comportamiento de las percepciones como aproximación útil para la comprensión y análisis espacial de la percepción de estos riesgos en el país.

Los resultados se articulan especialmente con la comprensión de la dinámica hidrológica natural o eventual extrema de cada localidad y la subjetividad del individuo, con relación a la consideración del riesgo al peligro concreto, sin marginar el conocimiento de la geografía local como fundamento para el desarrollo de actividades de educación en torno a la ocurrencia de estos fenómenos diferenciables en su intensidad localmente. 
Pablo Bayón-Martínez - Lilia Susana Padilla y Sotelo

Geographic vision of the perception of risks due to extreme hydrometeorological hazards in Cuba

\section{Referencias}

Almaguer, C. (2008). El riesgo de desastres: una reflexión filosófica. (Tesis doctoral. Ministerio de Educación Superior). Universidad de La Habana Facultad de Filosofía, Departamento de Filosofía. Cuba.

Bayón, P. (2012). El pensamiento geográfico y la percepción de riesgo por peligros naturales: contribución a la formación ambiental local. En: VI Congreso de Geografía Tropical; 14-18/mayo/2012, ISBN-978-959-282-09-1, La Habana, Cuba, consultado: 18-32019. Recuperado de: http://biblioteca.filosofia.cu/php/export. php? format $=$ htm\&id $=2690 \&$ view $=1$

Bayón, P. (2016a). El pensamiento geográfico en la percepción de riesgos por peligros hidrometeorológicos extremos: estudio de caso Mariel, Cuba. Revista Geográfica de América Central 56 (enero-junio), 113-135.

Bayón, P. (2016b). La percepción de riesgo por peligros hidrometeorológicos extremos en Cuba: mirada desde el entorno geográfico. Trayectorias 18 (julio-diciembre), 53-72

Boisier, S. (2004). Desarrollo territorial y descentralización. El desarrollo en el lugar y en las manos de la gente. Revista EURE V XXX, (90), 27-40.

Calderón, G. (2001). Construcción y reconstrucción del desastre. Ed. Plaza y Valdés, S.A de C.V., México. Consultado 17-08-2018, Recuperado de: https://books.google.com.cu/books?id=azvKUFS5c9YC\& printsec $=$ frontcover\&hl $=$ es $\&$ source $=$ gbs_ge_summary_r $\&$ cad $=0 \# \mathrm{v}$ $=$ onepage $\& \mathrm{q} \& \mathrm{f}=$ false

Calero, J. L. \& Santana, F. (2001). Percepciones de un grupo de adolescentes sobre iniciación sexual, embarazo y aborto. Revista Cubana de Salud Pública, 27(1), 50-57.

Cardona, O. (2003). ¿Cultura de la prevención de desastres? En: Seguridad Sostenible. Gobernanza y Seguridad Sostenible. Retrieved 15 de junio, 2010, from http://www.iigov.org/ss/article. drt?edi $=181749$ \&art $=181756$.

Engels, F. (2002). Dialéctica de la Naturaleza. Editorial Pueblo y Educación, La Habana, Cuba.

Espina, M; Núñez, L.; Martín, L.; Vega, L. (2002): Aspectos territoriales de las percepciones ambientales de la sociedad cubana. Informe integrado de los estudios territoriales CIPS. Citma, La Habana, Cuba. 
Fernández, A. and R. Pérez, Eds. (2009). GeoCuba Evaluación del medio ambiente cubano. La Habana.

Gellert de Pinto, G. I. (2012). El Cambio de paradigma: de la atención de desastres a la gestión del riesgo, Boletín científico Sapiens Research, 2(1), 13-17. Consultado: 8-12-2017]. Disponible en: https://dialnet. unirioja.es/servlet/articulo? codigo $=3841348$

GER-AMA. Grupo de Evaluación de Riesgo de la Agencia de Medio Ambiente, Cuba. (2013): Base de Datos Nacional, de percepción de riesgo por peligros hidrometeorológicos 2009-2011. Grupo de PVRAMA. [Elaborado por: Cristina López-Calleja Hiort-Lorenzen, Lilia Núñez Moreno, Elizabeth Godefoy Núñez.

González, I. (1996). Ambiente y Desarrollo. Reflexiones acerca de la relación entre los conceptos: ecosistema, cultura y desarrollo. 1996.

Hewitt, K. (1995). Excluded Perspectives in the Social Construction of Disaster. In: International Journal of Mass Emergencies and Disasters. November, 13(3), 317-339.

Hidalgo, A., Mitrani, I. \& Pérez, G. (2017). Nueva clasificación de las inundaciones costeras en Cuba. Revista Cubana de Meteorología, 23(2), 209-216.

Kates, R. (1971). Natural Hazard in Human Ecological Perspective: Hypotheses and Models. Economic Geografphy, 438-451.

López-Callejas, C., Núñez, L. (2011). Percepción del peligro de la población cubana, para los estudios de peligro, vulnerabilidad y riesgos tres provincias occidentales. Novedades en población, Revista del Centro de Estudios Demográficos de la Universidad de La Habana, Vol. 7, núm. 13 (2011). Consultado: 18 de abril de 2019. Recuperado de: http://www.novpob.uh.cu/index.php/NovPob/article/view/159

López-Callejas, C.; Núñez, L.; Godefoy, E. (2013). Principales resultados de los estudios de Percepción de los peligros: fuertes vientos, fuertes lluvias y penetración del mar, en Cuba. XXIX CONGRESO LATINOAMERICANO DE SOCIOLOGIA (ALAS). Santiago de Chile.

Maskrey, A. (1993). Vulnerabilidad y mitigación de desastres. Los desastres no son naturales. R. d. E. S. e. P. d. D. e. A. Latina. Panamá.

Mateo, J. (2011). Geografía de los paisajes. Primera parte. Paisajes naturales. Editorial Félix Varela, La Habana, 198 p.; ISBN-978-959-07-1617-1. 
Mateo, J. (2013). Teoría y Metodología de la Geografía. Ministerio de Educación Superior, Cuba. La Habana.

Mateo, J. y E. D. Silva. (2006). Para una interpretación epistemológica de la Geografía a partir de la Dialéctica. Mercator, Revista de Geografía da UFC 9(4): 55-68.

Maya, A. (1996). El reto de la vida: ecosistema y cultura. Una introducción al estudio del medio ambiente. Serie Construyendo el Futuro No. 4. Santafé de Bogotá, Distrito Capital de Bogotá: Ecofondo.

Mitrani, I.; Salas, I.; Ballester, M. y Y. Juantorena. (2011). "Penetraciones del mar en la zona costera del Golfo de Batabanó por afectación de sures, con escenario actual y previstos por posible incremento del nivel medio del mar". Boletín SOMETCUBA, Vol. 6, No. 1. Publicación Electrónica; http: www.met.inf.cu.

Núñez, L.; Espina, M. (2001). Percepciones ambientales y cotidianidad. Estudios de caso: Nuevitas y Ciénaga de Zapata. Informe de investigación. La Habana, Provincia de La Habana: Centro de Investigaciones Psicológicas y Sociológicas.

Núñez, L.; Espina, M. Marín, L; Vega, L.; Rodríguez, A.; Ángel, G. (2008). Perspectiva metodológica en las percepciones socioambientales. Población cubana y comunidades locales. La Habana.

Oficina nacional de estadística e información (ONEI). (2012). Anuario Estadístico de Cuba. (ed.2013). Consultado: 20-05-2014. Recuperado de: http://www.one.cu/aec2012/datos/00\%20ANUARIO\%20ESTADISTICO\%20DE\%20 CUBA\%202012.pdf Onei.

Oficina nacional de estadística e información (ONEI) (2018). Anuario Estadístico de Cuba 2017., (ed. 2018), Medio Ambiente. Consultado: 10-03-2019. Recuperado de: http://www.one.cu/aec2017/02\%20 Medio\%20Ambiente.pdf

Ojeda, A. \& Cuevas, A. (2014). Percepción del riesgo en la zona conurbada Colima-villa de Álvarez, frente al discurso del cambio climático. La construcción del futuro: retos de las Ciencias Sociales n México. . r. y. e. Memorias del 4to Congreso Nacional de ciencias Sociales; IV Sociedad y ambiente: vulnerabilidades. Tijuana. México, Publicado por CESMECA-UNICAHC, Tuxtla Gutiérrez y COMECSO. 
Planos, E., Vega, R. y Guevara, A. (eds.) (2013). Impacto del cambio climático y medidas de adaptación en Cuba. La Habana, Provincia de La Habana: Instituto de Meteorología. Agencia de Medio Ambiente. Ministerio de Ciencia, Tecnología y Medio Ambiente.

Plapp, T. (2001). Perception and evaluation of natural risk. Risk Research and Insurance Management. Working Papper 1: 11.

Quiroga, A. (1986). "Psicología Social como crítica de la vida cotidiana". En: A. Quiroga y J. Rueda. Crítica de la vida cotidiana. Ediciones Cinco, Buenos Aires, 6 $6^{\mathrm{a}}$ edición, 2003. Consultado: 1412-2017. Recuperado de https://es.scribd.com/doc/130892180/ Critica-de-La-Vida-Cotidiana-Ana-Quiroga\#

Santos, M. (1996). La naturaleza del espacio. Técnica y tiempo. Razón y emoción. Consultado: 8 de septiembre, 2014. Recuperado de: https:/geografiacriticaecuador.files.wordpress.com/2013/01/santosla-naturaleza-delespacio.pdf.

Sjöberg, L. (2003). The Different Dynamics of Personal and General Risk. Risk Management 5(3), 19-34.

Tserej, O. \& Febles, M. (2015). La escuela cubana como contexto para el correcto desarrollo de la percepción ambiental. Revista Complutense de Educación, 1 (26). Consultado: 21-7-2016). Recuperado de: https:// revistas.ucm.es/index.php/RCED/article/viewFile/42335/44225

Wenger, D. (1978). Community Response to Disaster. In: Quarantelli, E.L (ed.) Disasters: Theory and Research. California, Sage. Pp 17-47. White, F. (1974). Natural Hazars. Nueva York.

Wiedemann, P. M. (1993). Introduction risk perception and risk communication. Forschungszentrum Jülich. 